\title{
Pengurusan Kewangan di Agensi Kerajaan Persekutuan Malaysia : Keberkesanan Audit Dalam
}

\author{
Financial Management in Government Agencies
}

\author{
Mohd Aidil, A.A. \\ Fakulti Pengurusan dan IT, Universiti Sultan Azlan Shah, \\ Bukit Chandan, 33000, Kuala Kangsar, Perak, Malaysia. \\ Tel: +6016-5658796 E-mail: aidil@usas.edu.my \\ Suzaihan, S. \\ Fakulti Pengurusan dan IT, Universiti Sultan Azlan Shah, \\ Bukit Chandan, 33000, Kuala Kangsar, Perak, Malaysia. \\ Tel: +6016-2306900 E-mail: suzaihan@usas.edu.my \\ Noorhaslinda, Z.A \\ Fakulti Pengurusan dan IT, Universiti Sultan Azlan Shah, \\ Bukit Chandan, 33000, Kuala Kangsar, Perak, Malaysia. \\ Tel: +6019-6642652 E-mail: noorhaslinda@usas.edu.my
}

\begin{abstract}
Abstrak
Indeks Keamanan Dunia (Global Peace Index) adalah suatu usaha untuk mengukur kedudukan relatif sesuatu negara atau wilayah dari aspek keamanan. Salah satu kayu ukurannya ialah aras ketelusan yang tinggi dalam pentadbiran kerajaan. Namun begitu, pembentangan Laporan Ketua Audit Negara bagi tahun 2015 dan 2016 telah mendedahkan beberapa kelemahan pengurusan kewangan di agensi Kerajaan Persekutuan Malaysia. Secara teorinya, jika audit dalam berfungsi secara berkesan, fenomena tersebut sepatutnya tidak berlaku. Tidak dinafikan bahawa faktor dalaman dan luaran dapat menyumbang pada keberkesanan audit dalam tersebut. Antara faktor luaran ialah kerjasama auditee dan sokongan pengurus atasan. Justeru, objektif utama kajian ini adalah untuk mengkaji hubungan faktor luaran iaitu kerjasama auditee dan sokongan pengurus atasan dengan keberkesanan audit dalam di agensi Kerajaan Persekutuan di Malaysia. Sebanyak 240 soal selidik telah berjaya dikumpulkan daripada responden yang merupakan staf Unit Audit Dalam. Analisis secara kuantitatif meliputi ujian deskriptif dan
\end{abstract}

Regresi Pelbagai dengan menggunakan perisian IBM Statistical Package for Social Science Statistic (IBM SPSS).

Hasil kajian menunjukkan bahawa kerjasama auditee dan sokongan pengurus atasan dapat menyumbang pada keberkesanan audit dalam di Agensi Kerajaan Persekutuan Malaysia. Hasil kajian ini dapat meningkatkan kefahaman teoritis tentang peranan kerjasama auditee dan sokongan pengurus atasan demi meningkatkan keberkesanan audit dalam dan menjadikan kayu ukuran untuk menilai prestasi dan keberkesanan audit dalam di agensi Kerajaan Persekutuan di Malaysia.

Kata kunci: audit dalam; auditee; pengurus atasan; pengurusan kewangan

\begin{abstract}
The Global Peace Index (GPI) is a way of measuring in relative terms how a country or area performs from the perspective of security. One of the yardsticks of the GPI is the measure of transparency in government administration. Interestingly, the audit report tabled by the
\end{abstract}


Malaysian Auditor General for the year 20152016 has revealed a systemic weakness in the financial management of governmental federal agencies. Theoretically speaking, had the internal auditing been performing effectively, such a problem would not have occurred. It is undeniable that there are internal and external factors that may actually be useful in ensuring the effectiveness of internal auditing. Among the external factors is the cooperation between the agency being audited and the support given by the top management. The primary objective of this research therefore is to study the relationship between the external factors, that is, between the agency-management cooperation, and the effectiveness of internal auditing. As many as 240 questionnaires were successfully collected from the respondents from the internal audit unit. A quantitative analysis has been conducted involving not just a descriptive analysis but also, a multiple regression analysis that utilizes the IBM SPSS software package. Research results show that the cooperation between the agency that is being audited and the support coming from the top management positively contributed to the effectiveness in internal auditing in Malaysian federal government agencies. The finding of this research will enable the increase in theoretical understanding of the role of cooperation between an auditee and executive management support that ultimately points to the effectiveness of internal auditing and the benchmarking of performance assessment in the Malaysian government federal agencies.

Keyword: Internal Audit; Auditee; Top Management; Financial Management

\section{Pendahuluan}

Tidak dapat dinafikan bahawa salah satu indikator untuk mengukur kemanan sesuatu negara atau wilayah ialah aras ketelusan tinggi dalam pentadbiran kerajaan. Namun begitu, Laporan Ketua Audit Negara bagi tahun 2014, 2015 dan 2016 siri 1 yang dibentang telah mendedahkan beberapa kelemahan pengurusan kewangan di agensi Kerajaan Persekutuan Malaysia. Antara perkara yang telah didedahkan adalah sebanyak
895 teguran audit iaitu 748 atau 84 peratus teguran pembetulan manakala 103 atau 11 peratus teguran hukuman (Laporan Ketua Audit Negara 2016 Siri 1). Salah satu mekanisme yang wujud dalam jentera pentadbiran kerajaan demi memastikan tercapainya akauntabiliti dan terjamin ketelusan pengurusan kewangan ialah kawalan dalaman yang dilaksanakan oleh unit audit dalam.

Audit dalam memberi sumbangan dan berperanan penting dalam sesebuah organisasi sektor kerajaan mahupun sektor swasta dari aspek-aspek membantu untuk mengenalpasti dan mencegah daripada berlakunya penyelewengan (Mu'azu Saidu \& Siti Zabedah, 2014); membantu organisasi mencapai objektifnya dengan berkesan (Arena \& Azzone, 2010); memudahkan sesebuah organisasi mencapai tahap pencapaian yang terbaik dan menguntungkan serta menghalang sebarang perkara yang boleh menjejaskan kutipan hasil sektor kerajaan (Vijayakumar \& Nagaraja, 2012); mampu memainkan peranan untuk mencegah berlakunya amalan rasuah dan menyokong amalan urus tadbir yang baik (Virginia et al., 2009)

Walau bagaimanapun, penyelidik sebelum ini turut menguji beberapa faktor yang dianggap dapat memberi impak pada pelaksanaan audit dalam yang kurang berkesan. Faktor-faktor tersebut boleh dikategorikan kepada beberapa kumpulan iaitu yang berkaitan dengan:

a.) staf seperti kekurangan staf audit, staf audit yang kurang mahir tentang teknik audit, atau pun staf yang kurang berpengalaman ( Halimah et al., 2009);

b.) pengurusan seperti kurang sokongan dan komitmen daripada pihak pengurusan atasan, keterbatasan untuk mengakses sumber maklumat, dan kurang kerjasama daripada auditee (Cohen \& Sayag, 2010; Halimah et al., 2009); dan

c.) audit dalam sendiri seperti ciri-ciri audit dalam yang kurang berkualiti (Cohen \& Sayag, 2010); kedudukan unit audit dalam 
yang tidak bersifat bebas di sesebuah organisasi (Arena \& Azzone, 2009); sumber-sumber yang tidak mencukupi dan kurang kerjasama antara unit audit dalam dengan juruaudit luar (Halimah et al., 2009), jurang antara unit audit dalam dengan pihak jawatankuasa audit (Arena \& Azzone, 2009; Halimah et al., 2009), dan komponen sistem kawalan dalaman yang kurang berkesan (Karagiorgos, Drogalas, \& Giovanis, 2011).

Namun begitu, beberapa faktor luaran mampu membantu meningkatkan keberkesanan audit dalam dalam pengurusan kewangan. Salah satu faktor tersebut ialah kerjasama auditee. Kerjasama auditee merujuk pada sebarang aktiviti, dokumen dan rekod yang memudahkan juruaudit dalam untuk akses serta tahap kerjasama yang diberikan oleh auditee (Ejaz, Khalid, \& Riaz, 2011). Laporan kajian oleh Ninlaphay, Ussahawanitchakit, \& Boonlua (2012) menunjukkan bahawa kerjasama auditee mempunyai hubungan dengan keberkesanan audit dalam. Hasil kajian mereka konsisten dengan hasil kajian yang pernah dilaporkan oleh penyelidik lalu (Ejaz, Khalid, \& Riaz, 2011; Teck \& Ali, 2008). Hubungan auditee dengan juruaudit dalam adalah penting kerana ia mempermudah tugas audit dalam, meningkatkan kepuasan bekerja, meningkatkan keberkesanan organisasi sekaligus meningkatkan prestasi organisasi (Ejaz, Khalid, \& Riaz, 2011; Ninlaphay, Ussahawanitchakit, \& Boonlua, 2012).

Selain itu, faktor sokongan pihak pengurus atasan mempunyai hubungan yang signifikan dengan keberkesanan audit dalam (Annuar et al., 2009; Cohen \& Sayag, 2010; Halimah et al., 2009). Sokongan pihak pengurus atasan bermaksud pengurusan atasan mengambil tindakan terhadap dapatan dan cadangan audit dalam, menyediakan staf audit yang mencukupi, membekalkan kemudahan yang sesuai, menawarkan ganjaran yang setimpal serta menghantar staf unit audit dalam menjalani kursus luaran (Cohen \& Sayag, 2010;
Halimah et al., 2009). Halimah et al. (2009), menegaskan bahawa sokongan pihak pengurus atasan adalah penting kerana tanpa sokongan mereka sukar bagi unit audit dalam untuk menjalankan fungsinya dan sukar memperkukuh sesebuah organisasi yang diaudit.

Oleh itu, kajian ini bertujuan untuk menguji hubungan antara kerjasama auditee dan sokongan pengurus atasan dengan keberkesanan audit dalam di agensi Kerajaan Persekutuan di Malaysia.

\section{Metodologi}

Pengumpulan data dan maklumat berkaitan audit dalam ini dilakukan dengan menggunakan dua kaedah iaitu kaedah dokumentasi dan kaedah borang soal selidik. Kajian ini dimulakan dengan mengumpulkan beberapa maklumat daripada Laporan Ketua Audit Negara bagi tahun 2014, 2015 dan 2016. Bagi tujuan mendapatkan data yang tepat serta mencapai objektif kajian, maka soal selidik diemelkan. Soal selidik merupakan instrumen kajian yang paling popular digunakan untuk memperoleh data (Rattray \& Jones, 2007). Hal ini konsisten dengan beberapa kajian lalu yang menghantar soal selidik kepada staf audit dalam untuk menguji keberkesanan audit dalam di sektor kerajaan mahupun di sektor swasta (Abbot, Parker, \& Peters, 2010; Cohen \& Sayag, 2010; Christopher et al., 2009).

Rangka pensampelan bagi kajian ini merupakan direktori staf di Unit Audit Dalam yang diperoleh daripada laman web Jabatan Audit Negara serta laman web bagi setiap agensi tersebut Daripada 300 soal selidik , hanya 240 soal selidik berjaya dikumpulkan daripada 129 Agensi Kerajaan Persekutuan di Malaysia. Data yang dikumpulkan telah dikodkan dengan sistematik menggunakan perisian IBM Statistical Package for Social Sciences (IBM SPSS). Analisis kajian melibatkan analisis kesahan dan kebolehpercayaan instrumen serta analisis sampel kajian. Nilai Alfa Cronbach yang dicatatkan bagi konstruk kerjasama auditee ialah 0.82 manakala sokongan pengurus atasan mencatatkan 0.73. Analisis secara deskriptif 
diguna pakai untuk menganalisis demografi responden. Ujian regresi pelbagai statistik, prosedur penyelesaian stepwise digunakan kerana lebih ekonomi dan hanya pemboleh ubah peramal yang signifikan sahaja dimasukkan dalam persamaan regresi. Tambahan pula, prosedur ini dapat menggelakkan masalah multicollinearity yang berlaku akibat korelasi yang kuat antara pemboleh ubah-pemboleh ubah peramal. Ujian regresi seperti ini turut digunakan oleh pengkaji-pengkaji dalam bidang audit dalam seperti Suyono \& Hariyanto (2012) serta Alzeban \& Gwilliam (2012).

\section{Hasil dan Perbincangan}

Jadual 1:Taburan Frekuensi Jantina Responden

\begin{tabular}{|c|c|c|}
\hline Jantina & Frekuensi & Peratus \\
\hline Lelaki & 73 & 30.4 \\
\hline Perempuan & 167 & 69.6 \\
Jumlah & $\mathbf{2 4 0}$ & $\mathbf{1 0 0}$ \\
\hline
\end{tabular}

Berdasarkan Jadual 1 di atas, majoriti responden terdiri daripada golongan perempuan iaitu $69.6 \%$ sedangkan peratusan golongan lelaki mencatatkan 30.4\%.

Jadual 2: Taburan Frekuensi Pengalaman Bertugas di Unit Audit Dalam

\begin{tabular}{|l|c|c|}
\hline Tempoh Pengalaman & Frekuensi & Peratus \\
\hline Bawah 1 tahun & 15 & 6.3 \\
\hline Lebih 1 hingga 5 tahun & 135 & 56.3 \\
\hline 6 hingga 10 tahun & 42 & 17.4 \\
\hline Lebih 10 tahun & 48 & 20.0 \\
Jumlah & $\mathbf{2 4 0}$ & $\mathbf{1 0 0}$ \\
\hline
\end{tabular}

Merujuk pada Jadual 2 di atas, kebanyakan responden mempunyai pengalaman bertugas di UAD antara lebih 1 tahun hingga 5 tahun iaitu 135 orang responden (56.3\%). Manakala, minoriti mencatatkan 15 orang responden $(6.3 \%)$ memiliki pengalaman bertugas di UAD kurang setahun.

Jadual 3:Taburan Frekuensi Kelayakan Profesional Responden
\begin{tabular}{|l|l|l|}
\hline $\begin{array}{l}\text { Kelayakan } \\
\text { Profesional }\end{array}$ & Frekuensi & Peratus \\
\hline Ada & 17 & 7.1 \\
\hline Tiada & 223 & 92.9 \\
Jumlah & 240 & 100 \\
\hline
\end{tabular}

Dari segi kelayakan profesional, jadual di atas menunjukkan 17 orang responden (7.1\%) memiliki kelayakan profesional manakala bakinya tiada memiliki sebarang kelayakan profesional.

Jadual 4: Ringkasan Model Regresi Pelbagai ${ }^{\mathrm{c}}$
\begin{tabular}{|l|l|l|l|l|}
\hline & R & R Square & $\begin{array}{l}\text { Adjusted R } \\
\text { Square }\end{array}$ & $\begin{array}{l}\text { Std. Error of the } \\
\text { Estimate }\end{array}$ \\
\hline 1 & $.613 \mathrm{a}$ & .376 & .373 & .307 \\
\hline 2 & $.632 \mathrm{~b}$ & .400 & .395 & .302 \\
\hline
\end{tabular}

a. Peramal: (Konstan), kerjasama Auditee

b. Peramal: (Konstan), Kerjasama Auditee, Sokongan Pengurus Atasan

c. Pembolehubah Tidak Bebas: Keberkesanan audit dalam

Berdasarkan Jadual 4 di atas, Secara signifikan, kerjasama auditee menyumbang sebanyak $37.6 \%$ varians $\left(\mathrm{R}^{2}=.376\right)$ dalam keberkesanan audit dalam di Agensi Kerajaan Persekutuan Malaysia. Ini bererti bahawa kerjasama auditee $(\beta=.44, p<.05)$ merupakan petunjuk utama yang menyebabkan keberkesanan audit dalam. Manakala, kombinasi kerjasama auditee dan sokongan pengurus atasan menambah sebanyak 2.4 peratus $(40.0 \%-37.6 \%)$ kepada varians dalam pemboleh ubah kriterion keberkesanan audit dalam di Agensi Kerajaan Persekutuan Malaysia. Berdasarkan keputusan analisis, kajian melaporkan bahawa kerjasama auditee dan sokongan pengurus atasan merupakan pembolehubah peramal bagi keberkesanan audit dalam di Agensi Kerajaan Persekutuan Malaysia. 


\section{Kesimpulan}

Secara kesimpulannya, dapatan kajian ini bermaksud keberkesanan audit dalam dapat ditingkatkan jika auditee memberi kerjasama yang baik semasa juruaudit dalam menjalankan tugasnya. Selain itu, pengurus atasan yang memberikan sokongan yang baik mampu meningkatkan keberkesanan audit dalam di Agensi Persekutuan Malaysia. Jika audit dalam dapat ditingkatkan maka kelemahan pengurusan kewangan di Agensi Persekutuan Malaysia dapat diminimumkan sekaligus meningkatkan urus tadbir baik kerajaan Malaysia di mata dunia.

\section{Rujukan}

A.N.Vijayakumar \& Dr. N. Nagaraja. (2012). Internal control systems: effectiveness of internal audit in risk management at public sector entreprises. BVIMR Management Edge, $5(1), 1-8$

Abbott, L. J., Parker, S., \& Peters, G. F. (2010). Serving two masters: the association between audit committee internal audit oversight and internal audit activities. Accounting Horizons, 24(1), 1-24.

Arena, M., \& Azzone, G. (2007). Internal audit departments: adoption and characteristics in Italian companies. International Journal of Auditing, 11(2), 91-114.

Arena, M., \& Azzone, G. (2009). Identifying organizational drivers of internal auditeffectiveness. International Journal of Auditing,13(1), 43-60.

Badara, M.S. \& S.Z. Saidin. (2014). Empirical evidence of antecedents of internal audit effectiveness from Nigerian perspectives. Middle-East Journal of Scientific Research, 19 (4), 460-71.

Beling J., Libertini L. S., \& Sun Z. (2011).
Predictors for electronic survey completion in healthcare research. Computers, Informatics, Nursing, 29(5), 297-301.

Bhasah Abu Bakar (2007). Kaedah analisis data penyelidikan ilmiah. Kuala Lumpur, Malaysia : Utusan Publications \& Distributors Sdn Bhd.

Bota-Avram, C. \& Palfi, C. (2009). Measuring and assessment of internal audit's effectiveness. Economic Science Series. Annals of the University of Oradea, 183, 784-90.

Brindle S., Douglas F., \& Van Teilungen, E. (2005) Midwifery research: questionnaire surveys. Midwives. 8(4), 156-8.

Christopher, J., Sarens, G., \& Leung, P. (2009). A critical analysis of the independence of the internal audit function: evidence from Australia. Accounting, Auditing \& Accountability Journal, 22(2), 200-20.

Cohen,A., \& Sayag, G. (2010). The Effectiveness of Internal Auditing: An Empirical Examination of its Determinants in Israeli Organisations. Australian Accounting Review, 296-307.

Desai, V., Roberts R. W., \& Srivastava R. P. (2010). An analytical model for external auditor evaluation of the internal audit function using belief functions. Retrieved 04/23/09, from http://ssrn.com/paper=938183

Dittenhofer, M. (2001). Internal audit effectiveness: an expansion of present methods. Managerial Auditing Journal, 16(8), 443-50.

Ebimobowei, A., \& Kereotu, O. J. (2011). Role Theory and the concept of audit expectation gap in South-south Nigeria. Current Research Journal of Social Sciences, 3(6), 445-52

Ejaz, R., Khalid, F., \& Riaz, A. (2011). Employees' participation in decision making (actual vs perceived): A study of the Telecom Sector of Pakistan. Journal of Contemporary Research in Business, 3, 1551-58 
Fadzil, F. H., Haron, H., \& Jantan, M. (2005). Internal auditing practices and internal control system. Managerial Auditing Journal, 20(8), 844-66.

Gay, G., \& Simnett, R. (2007). Auditing and assurance services in Australia. Revised 3rd Edition. Sydney: McGraw-Hill Australia.

Gramling, A., \& Hermanson, D. (2009). Internal audit quality: would we know it if we saw it ?. Internal Auditing, 24(1), 36-9.

Iraldo, F., Testa, F., \& Frey, M. (2009). Is an environmental management system able to influence environmental and competitive performance: the case of the ecomanagement and audit scheme (EMAS) in the European Union. Journal of Cleaner Production, 17(16), 1444-52

Karagiorgos T., Drogalas G., \& Giovanis N. (2011). Evaluation of the effectiveness of internal audit in Greek Hotel Business. International Journal of Economic Sciences and Applied Research, 4(1), 19-34.

Matarneh, Ghassan. F. Al. (2011). Factors Determining the Internal Audit Quality in Banks: Empirical Evidence from Jordan. International Research Journal of Finance and Economics, 73, 1450- 2887.

Mat Zain, M., \& Subramaniam, N. (2007). Internal auditor perceptions on audit committee interactions: a qualitative study in Malaysian public corporations. Corporate Governance, 15(5), 894-908.

Mat Zain, M., Subramaniam, N., \& GoodwinStewart, J. (2006). Internal auditors assessment of their contribution to financial statement audits: the relation with audit committee andinternal audit function characteristics. International Journal of Auditing, 10(1),1-18.

Mihret, D. G., \& Yismaw, A.W. (2007). Internal audit effectiveness: an Ethiopian public sector case study. Managerial Auditing Journal, 22(5), 470-84.

Mihret, D. G., James K., \& Mula J. M. (2010). Antecedents and organizational performance implications of internal audit effectiveness: some propositions and research agenda. Pacific Accounting Review, 22(3), 224-52.

Mohamud, H. A.(2013). Internal auditing practices and internal control systems in Somalia remittance firms. International Journal of Business and Social Sciences, 4(4), 165-72.

Mohd Noor Azli \& Noor Azizi. (2009). Pelaporan kewangan menerusi internet: perspektif teori kontingensi. Jurnal Kemanusiaan, 14, 68-84.

Mu'azu Saidu Badara \& Siti Zabedah Saidin. (2014). Empirical evidence of antecedents of internal audit effectiveness from Nigerian perspective. Middle-East Journal of Scientific Research, 19 (4), 460-71.

Nagy, A. L., \& Cenker, W. J. (2002). An assessment of the newly defined internal audit function. Managerial Auditing Journal, 17(3), 130-7.

Ninlaphay, S., Ussahawanitchakit, P., \& Boonlua, S. (2012). Internal control system effectiveness and on going firm sustainability: evidence from financial businesses in Thailand. Journal of International Finance and Economics, 12(2), 61-84.

Norazlisham, M. A., Norhashim, M., \& Hassan, N. A. (2012). Do they think alike ? Perception analysis on Quality Environment (QE) audit effectiveness: a Malaysian case. Journal of Accounting and Auditing: Research \& Practices, 2012, 1-8.

Octavia, E., \& Yuliani, R. (2011). Role of internal audit in supporting effectiveness of internal control micro credit. Proceedings of International Seminar on Business and Management, (20-26). Bandung, Indonesia. 
Pongpanpattana, J., \& Ussahawanitchakit, P. (2012). Intelligent learning, internal audit report and internal audit performance: empirical evidence from Thai-listed firms. Journal of International Finance and Economics, 12(2), 49-60.

Ramachandran, J., Subramanian, R. \& I.J. Kisoka. (2012). Effectiveness of internal audit in Tanzanian Commercial Banks. British Journal of Arts and Social Sciences, 8(1), 32-44.

Rattray J., \& Jones M. C. (2007) Essential elements of questionnaire design and development. Journal of Clinical Nursing, 16(2), 234-43.

Sari, R. N., Ainuddin, R. A., \& Tengku Abdullah, T. A. (2006). Kesan padanan antara perakaunan pengurusan strategik dengan strategi perniagaan terhadap prestasi firma. Jurnal Pengurusan, 25, 87-109.

Sterck, M., \& Bouckaert, G. (2006). International audit trends in the public sector. The Internal Auditor, 63(4), 49-53.
Sue V. M., \& Ritter L. A. (2007). Conducting Online Surveys. Sage Publications, Thousand Oaks CA

Suyono E., \& Hariyanto E. (2012). Realtionship between internal control, internal audit, and organization commitment with good governance: Indonesian case. China-USA Business Review, 11(9), 1237-45.

Teck, H. L., \& Ali, A. (2008). Audit challenges in Malaysia today. Accountants Today, October 2008, 24-26.

V. Mohammadzadeh, Kangarlouei S.J., Motavasse1, M. (2012). Evaluation of internal audit effectiveness in Tehran Stock Exchange (TSE). Research Journal of Business Management and Accounting, 1(2), 19-24.

Virginia, A., Eleni, K., Dimitrios, P., \& Chrysoula, X. (2009). The role of financial accounting information in strengthening corporate control mechanisms to alleviate corporate corruption (University Macedonia Working Paper). Retrieved from http://www. google.com/pdf 
